para resolver satisfactoriamente los problemas que provoca la falta de dedicación y empeño en proyectos de desarrollo de capacidades. El fortalecimiento de las capacidades del gobierno central y de las autoridades regionales parece enfrentar problemas permanentes, como los trámites burocráticos, el cambio constante de personal, la sobrecarga de trabajo, los bajos salarios y las presiones políticas para abandonar los planes promovidos por la anterior administración. La asociación entre universidades, ONG y organizaciones privadas de carácter voluntario puede tener menos obstáculos, pero no está exenta de retos.

Los proyectos de desarrollo de capacidades no pueden desconocer estas condiciones a la hora de diseñar intervenciones, especialmente en países en desarrollo como Perú, donde el sistema público de salud, a pesar de sus limitaciones, hace un esfuerzo para ofrecer sus servicios a la mayoría de la población. Los proyectos de desarrollo de capacidades pueden orientar su trabajo hacia organizaciones de la sociedad civil, pero si no promueven el fortalecimiento de capacidades en las instancias de gobierno, sus acciones tendrán poco impacto en los programas de salud y, finalmente, en la población.

Es necesario promover un pensamiento creativo para reconceptualizar los programas de entrenamiento, una actividad obligada en cualquier proyecto de desarrollo de capacidades. Estos programas deben satisfacer las demandas institucionales y cumplir con las cuotas de participación en los entrenamientos. Sin embargo, el desarrollo de capacidades no es sinónimo de entrenamiento, especialmente cuando los sistemas de salud padecen un constante robo de cerebros, la moral es baja entre el personal y faltan incentivos institucionales para mejorar el desempeño laboral. En tales circunstancias, el impacto de las actividades de entrenamiento en la promoción de salud y en la salud pública puede durar poco.

El fortalecimiento de las capacidades implica establecer vínculos de colaboración entre las instituciones, estipulando claramente los términos de colaboración y garantizando que todas las partes se sientan igualmente comprometidas con los mismos resultados. Sin estas premisas, la responsabilidad compartida sería muy frágil y la asociación y las metas podrían ser efímeras. (Waisbord S. When training is insufficient: reflections on capacity development in health promotion in Peru. Health Prom Int. 2006;21(3):230-7.)

\section{Seroprevalencia y factores de riesgo de la infección por el VIH en trabajadoras sexuales de América del Sur}

La prevalencia de la infección por el virus de la inmunodeficiencia humana tipo 1 (VIH-1) varía considerablemente entre las poblaciones de trabajadoras sexuales de diferentes partes del mundo. Las mayores prevalencias se han encontrado en los países de África subsahariana (de 0,2\% a 60,5\%), seguidos de los del sur y el sudeste de Asia (hasta 26\%). En América Latina y el Caribe, según los datos disponibles, las tasas son menores (hasta $14,0 \%$ ) y la transmisión de la infección por VIH se concentra en otros grupos de alto riesgo, como los hombres que tienen sexo con hombres y los adictos a drogas inyectadas. Sin embargo, esta información es fragmentada e insuficiente.

En este artículo se resumen los datos de varios estudios transversales que en conjunto abarcaron 13600 trabajadoras sexuales de 32 ciudades de América del Sur representativas de la región andina (Bolivia: Santa Cruz; Colombia: Bogotá; Ecuador: Quito y Guayaquil; Perú: Lima, Iquitos, Pucallpa, Trujillo, Arequipa, Tacna y Sullana; y Venezuela: Isla Margarita) y del Cono Sur (Argentina: Buenos Aires y otras siete ciudades; Chile: Santiago; Paraguay: Asunción y otras cuatro ciudades; y Uruguay: Montevideo y cinco ciudades fronterizas con Brasil). El estudio se llevó a cabo entre 1999 y 2002 mediante cuestionarios anónimos aplicados en burdeles, salones de masaje, hoteles y calles. Se tomaron muestras de sangre para la detección serológica de la infección por VIH mediante pruebas inmunoenzimáticas del tipo ELISA y su confirmación se realizó mediante pruebas de western blot. Todas las participantes tenían 18 años de edad o más y aceptaron tomar parte en el estudio. Se calculó la razón de posibilidades ajustada por la edad (RPA).

La prevalencia general fue de 1,2\% y varió de 0,0\% (en Venezuela y Chile) a 4,5\% (en Argentina), con valores intermedios en los restantes países (Bolivia: 0,4\%, Colombia: 0,8\%, Uruguay: 0,8\%, Perú: 1,0\%, Ecuador: 1,8\% y Paraguay: 2,6\%). En conjunto, la prevalencia de VIH fue menor en los países de la región andina que en los del Cono Sur. Los factores de predicción de esta infección en la región andina fueron los antecedentes de infección de transmisión sexual (RPA $=3,8-8,3)$ y la vinculación al comercio sexual por más de 10 años (RPA $=2,2-24,8)$. El contacto sexual con más de tres clientes $(R P A=5,0)$, las relaciones sexuales con extranjeros $(\mathrm{RPA}=6,9 \%)$, el uso de drogas ilegales (RPA $=3,2$ ) y el consumo de marihuana ( $R P A=8,2)$ estuvieron asociados con la infección por VIH en los países del Cono Sur.

Estos resultados confirman que la prevalencia de la infección por el VIH es baja en las trabajadoras sexuales de América del Sur, especialmente en los países de la región andina. Se observó un aumento en la prevalencia en Argentina, Paraguay y Uruguay. En Argentina, 65\% de las mujeres infectadas se encontraron en la zona metropolitana de Buenos Aires. 
Este estudio constituye la mayor base de datos sobre la prevalencia de VIH en trabajadoras sexuales en América Latina y complementa uno similar realizado en hombres que tienen sexo con hombres. Estos resultados demuestran el papel cada vez mayor que desempeña el consumo de drogas ilegales en la transmisión de esta infección en la población sexualmente activa. Se deben diseñar intervenciones locales efectivas enfocadas hacia la salud pública y la educación, que alcancen a este vulnerable segmento de la población. Esas intervenciones se deben dirigir no solo al control de la transmisión del VIH, sino también al de otras enfermedades de transmisión sexual y deben ajustarse a las particularidades de cada región y país, en especial a los patrones sexuales y conductuales predominantes y a los factores de riesgo específicos de cada localidad. (Bautista CT, Sánchez JL, Montano SM, Laguna-Torres A, Suárez L, et al. Seroprevalence of and risk factors for HIV-1 infection among female commercial sex workers in South America. Sex Transm Infect. 2006;82:311-6.)

\section{Los determinantes sociales de la salud, la posición socioeconómica y la inequidad en salud}

El surgimiento de modelos teóricos acerca de los determinantes sociales de la salud ha añadido más ambigüedad conceptual a la comprensión de la inequidad social en salud, ya que con frecuencia no es posible distinguir claramente entre la posición socioeconómica y esos determinantes. Ya sea que las inequidades sociales en salud se basen en las diferencias sanitarias o en las diferencias de los determinantes sociales de la salud que están asociadas con la posición socioeconómica, los responsables de tomar las decisiones políticas deben conocer la importancia que tiene para la salud la posición socioeconómica. La falta de claridad en los informes de los investigadores es una de las razones que impiden que sus investigaciones tengan un mayor efecto positivo sobre la elaboración de políticas sanitarias. Esto no solo se debe a la gran cantidad de modelos, sino a la imposibilidad de definir en muchos de ellos si la posición socioeconómica es un concepto teórico independiente o si está asociado con los determinantes sociales.

En este artículo se expone cómo esa ambigüedad en la interpretación de la posición socioeconómica y de los determinantes sociales de la salud, así como el solapamiento conceptual de ambos términos, contribuyen a la falta de la necesaria claridad en la información sobre la salud pública.

El empleo de un solo modelo teórico para explicar la salud y las inequidades sociales en la salud puede hacer más difícil distinguir entre los determinantes sociales de la salud y los procesos sociales que determinan la distribución social desigual de esos determinantes. Por otra parte, no está claro si las clases sociales constituyen una dimensión de la posición socioeconómica, a pesar de que muchos autores aceptan que son conceptos independientes. Las clases sociales no son una propiedad preestablecida de las personas, sino una relación social creada por las sociedades y como tal, preceden lógica y materialmente a su expresión en la distribución de los ingresos, la riqueza, la educación y el estatus social. Es precisamente para referirse a estos componentes de bienestar social que se utiliza el término "posición socioeconómica".

También es necesario ponerse de acuerdo sobre lo que se entiende por determinantes sociales de la salud y si estos determinantes constituyen un concepto diferente de la posición socioeconómica. La situación socioeconómica es un importante factor de predicción de la exposición a muchos riesgos considerados determinantes sociales de la salud. Algunos autores consideran que el término "social" debe reservarse para designar los procesos de distribución de los peligros materiales, las conductas saludables y los factores psicosociales en los diversos grupos socioeconómicos.

Por último, es necesario identificar las dimensiones e indicadores más apropiados de la posición socioeconómica para evaluar el efecto de las intervenciones dirigidas a reducir las inequidades. Si se acepta que cada dimensión de la posición socioeconómica puede influir sobre la salud por diferentes vías y de esa forma ser más o menos trascendente para la salud, ¿puede emplearse cualquiera de esas dimensiones para evaluar el resultado de una intervención dirigida a reducir la inequidad económica? ¿O las dimensiones de la posición socioeconómica que se deben emplear dependen del tipo de intervención? ¿Cuál o cuáles de las diversas dimensiones de la posición socioeconómica se deben utilizar? ¿Los ingresos, el nivel educacional o algún indicador de la clase social? Estas preguntas no tienen una respuesta sencilla, pero es necesario responderlas antes de poder evaluar el desempeño de una intervención.

En conclusión, para resolver las ambigüedades analizadas se propone satisfacer los siguientes requisitos básicos: alcanzar un consenso sobre las dimensiones que reflejan la posición socioeconómica; acordar qué se debe considerar como determinante social de la salud y si estos determinantes son un concepto teórico independiente de la posición socioeconómica; y finalmente, establecer cuáles dimensiones e indicadores de la posición socioeconómica son las más apropiadas para evaluar las intervenciones dirigidas a reducir las inequidades 